\title{
Sensitivity and decisional factors in the psychological refractory period'
}

\author{
IRA H. BERNSTEIN, ${ }^{2}$ MARK H. CLARK, AND R. RANDOLPH BLAKE ${ }^{3}$ \\ UNIVERSITY OF TEXAS AT ARLINGTON
}

\begin{abstract}
Three trained Ss responded to a pair of events presented at fixed interstimulus intervals (ISIs) of 33, 67, and 100 msec. Each event was the independent presence of a visual stimulus (S-P) or its absence (S-A), to which Ss were to respond or not, with a set for speed over accuracy. The probabilities of $S-P$ occurrence $[P(S)]$ to each of the events were varied. Pretrial verbal reports or behavioral hypotheses (BHs) were also obtained. P(S), ISI, BH, and order (first vs second event) were all generally determinants of both $R T$ to $S-P$ and inhibition probability to $S$-A. However, when the $R T$ data were corrected for inhibition probability, order was the only systematic effect that remained. The results were discussed in terms of approaches to the psychological refractory period derived from signal detection theory involving differential sensitivity as opposed to criterion.
\end{abstract}

Since its development, the theory of signal detectability (TSD) has had extensive application because of its generality and the relevance of the sensory-decisional distinction to choice situations. The present paper is concerned with the application of TSD to a traditional problem in the reaction time (RT) literature, the psychological refractory period (PRP). The PRP is defined as a degradation in RT to the second of two closely spaced stimulus events, $S_{1}$ and $S_{2}$, and has been most recently reviewed by Smith (1967).

Bernstein, Blake, and Hughes (1967) obtai 'a PRP effect when an attempt was made $\downarrow$ sure complete task certain ty with event certainty and fixed time relations among $S_{1}$ and $S_{2} \cdot R T_{2}\left(R T\right.$ to $S_{2}$ ) was equal to $\mathrm{RT}_{1}\left(\mathrm{RT}\right.$ to $S_{1}$ ) when $S_{1}$ and $S_{2}$ were synchronous. As the interstimulus interval (ISI) separating $S_{1}$ and $S_{2}$ increased, $R T_{2}$ increased and then decreased relative to $R T_{1}$, again reaching equality at $100 \mathrm{msec}$ ISI.

The results supported a concept of the PRP based upon structural limitations in "doing two things at once." However, the lack of choice, necessary for theoretical considerations, failed to separate two possible factors that could have accounted for the effect. These will be termed sensitivity and criterion because of their conceptual similarity to these terms as used in TSD.

Suppose the RT task is to respond to the presence of a given event (S-P) but to inhibit in the absence of the event (S-A). Such variables as physical energy affect performance, as do other variables, e.g., instructions (Fitts, 1966). However, these two categories of variables affect RT by clearly different means. In the latter case, decreases in latency necessitate parallel increases in error rate and probability of inhibiting on S-A or check trials [P(I)]. The speed-error tradeoff phenomenon suggests that apparent RT differences produced by instructions would disappear following a suitable error-rate correction. On the other hand, one would not expect the former category of determinants to produce such "correctable" differences in performance.

These two categories of RT effects suggest a general parallelism of RT and TSD. Thus, correctable and uncorrectable RT differences would correspond to sensitivity and decisional effects, as the use of the ROC curve in TSD essentially seems to control statistically for error rate. However, to apply TSD logic to RT, it is not necessary to assume a complete isomorphism as to underlying mechanisms. Within TSD, various two-parameter models exist, providing a satisfactory explanation for most relevant data, yet proceeding from differing axioms (Luce, 1963).

The problems of errors in RT has been long recognized but, until recently (Fitts, 1966), not systematically explored. A consequence of this neglect has been the lack of generally accepted error-rate correction, although Yellott (1967) has recently approached the problem. Consequently, an empirical procedure, linear regression, was necessary in the present study. RT studies in general, and PRP studies in particular, traditionally have approached the problem of error by attempting to avoid it through attempts to achieve error-free performance, as was done in earlier psychophysical experiments. This strategy runs counter to the logic of TSD, which demands error rate be kept sufficiently high to allow assessment of S's response criterion. Thus, prior experimental results could not be used to see if the factors responsible for the PRP can be treated as a sensitivity deficit.
Because TSD-oriented RT models are fairly recent (McGill, 1963; Grice, 1968), extant explanations of the PRP are not directly phrased in sensitivity and decisional terms. However, many are easily translated by considering whether or not they would predict the delays in $\mathbf{R T}_{2}$ to remain under error-rate correction. For example, single-channel theory would treat the deficit as a sensitivity effect. Different versions of single-channel theory (Smith, 1967; Bernstein, Blake, \& Hughes, 1968) all assume a storage phase for $S_{2}$ prior to processing with short ISIs. Thus, after being equated for $\mathrm{P}(\mathrm{I}), \mathrm{RT}_{1}$ and $\mathrm{RT}_{2}$ would still differ by the duration of this storage phase. Conversely, preparatory-state theories (Poulton, 1950; Smith, 1967) may be interpreted as decisional if it is assumed that higher states of preparation facilitate responding but low states facilitate inhibition, i.e., response readiness behaves like inertia in physical systems. Hence, whereas $S s$ could respond more easily to $S_{1} \cdot P$ than $S_{2} \cdot P$, they would also be able to inhibit more easily $S_{2}-A$ as opposed to $S_{1}-A$. Although RT order differences would exist, they would vanish upon error-rate correction.

The purpose of the present study was to see if order differences in RT would or would not remain following error-rate correction as part of a general concern with the error-rate correction problem. A sequential Donder's Type $C$ task was used in which the occurrence probability of $S_{1}-P$, $\left[P\left(S_{1}\right)\right]$ was statistically independent of the occurrence probability of $S_{2} \cdot P,\left[P\left(S_{2}\right)\right]$. $P\left(S_{1}\right)$ and $P\left(S_{2}\right)$ were varied factorially across conditions at levels of .4 and .8 . The ISIs chosen were 33,67 , and $100 \mathrm{msec}$, as suggested from prior findings (Bernstein, Blake, \& Hughes, 1968). The instructions stressed speed over accuracy. Pretrial verbal reports or behavioral hypotheses (Bernstein, Schurman, \& Forester, 1967) were obtained from $S s$ regarding their expected pattern of events. The RT and $P(I)$ changes that occurred to the various combinations of $\mathrm{P}(\mathrm{S})$ and $\mathrm{BH}$ were then analyzed to explore ISI and order effects. Also, differences in performance to an event as a function of the presence or absence of the alternative event were examined to investigate whether it is the paying attention to a second channel or the presence of an overt response to stimuli 
Table 1

Mean RT and $z$ as a Function of $P\left(S_{1}\right), P\left(S_{2}\right)$, and ISI, Separately for Each $S$ and as a Composite

\begin{tabular}{|c|c|c|c|c|c|c|c|c|c|c|c|c|c|}
\hline \multirow[b]{3}{*}{$P\left(S_{1}\right)-P\left(S_{2}\right)$} & \multicolumn{7}{|c|}{ RT } & \multicolumn{6}{|c|}{$\mathbf{z}$} \\
\hline & \multicolumn{4}{|c|}{$\begin{array}{c}S_{1} \\
I S I\end{array}$} & \multicolumn{3}{|c|}{$\begin{array}{l}\mathbf{S}_{\mathbf{2}} \\
\mathbf{I S I}\end{array}$} & \multicolumn{3}{|c|}{$\begin{array}{l}S_{1} \\
\text { ISI } \\
\end{array}$} & \multicolumn{3}{|c|}{$\begin{array}{c}S_{2} \\
\text { ISI }\end{array}$} \\
\hline & $\mathbf{S}$ & 33 & 67 & 100 & 33 & 67 & 100 & 33 & 67 & 100 & 33 & 67 & 100 \\
\hline $.4-.4$ & $\begin{array}{l}\text { MC } \\
\text { RB } \\
\text { MT } \\
\text { Comp }\end{array}$ & $\begin{array}{l}422 \\
275^{b} \\
276 \\
324\end{array}$ & $\begin{array}{l}331 \\
250^{b} \\
288 \\
289\end{array}$ & $\begin{array}{l}301 \\
254 \\
302 \\
286\end{array}$ & $\begin{array}{l}433 \\
341 \\
303 \\
359\end{array}$ & $\begin{array}{l}358 \\
266 \\
307 \\
310\end{array}$ & $\begin{array}{l}326 \\
264 \\
309 \\
300\end{array}$ & $\begin{array}{l}2.29 \\
1.70 \\
2.01^{b} \\
2.00\end{array}$ & $\begin{array}{l}2.54 \\
1.83 \\
1.92 \\
2.10\end{array}$ & $\begin{array}{l}2.29 \\
1.91 \\
2.13 \\
2.11\end{array}$ & $\begin{array}{l}2.29 \\
2.01 \\
2.50 \\
2.27\end{array}$ & $\begin{array}{l}2.13 \\
1.25^{b} \\
2.54 \\
1.97\end{array}$ & $\begin{array}{l}2.13 \\
1.28 \mathrm{~b} \\
1.54^{\mathrm{b}} \\
1.65\end{array}$ \\
\hline $.4-.8$ & $\begin{array}{l}\text { MC } \\
\text { RB } \\
\text { MT } \\
\text { Comp }\end{array}$ & $\begin{array}{l}259 \\
266 \\
271 \\
265\end{array}$ & $\begin{array}{l}249 \\
286 \\
279 \\
271\end{array}$ & $\begin{array}{l}257 \\
258 \\
269 \\
261\end{array}$ & $\begin{array}{l}243 \\
238 \\
236 \\
239\end{array}$ & $\begin{array}{l}229 \\
222 \\
214 \\
221\end{array}$ & $\begin{array}{l}195 \\
214 \\
207 \\
205\end{array}$ & $\begin{array}{l}1.35 \\
2.01 \\
1.16 \\
1.51\end{array}$ & $\begin{array}{l}1.91 \\
1.76 \\
1.42 \\
1.70\end{array}$ & $\begin{array}{l}1.48 \\
2.01 \\
1.19 \\
1.56\end{array}$ & $\begin{array}{l}.52 \\
.43 \\
.34 \\
.43\end{array}$ & $\begin{array}{l}.34 \\
.30 \\
.34 \\
.33\end{array}$ & $\begin{array}{r}-.07 \\
.53 \\
.04 \\
.17\end{array}$ \\
\hline $.8-.4$ & $\begin{array}{l}\text { MC } \\
\text { RB } \\
\text { MT } \\
\text { Comp }\end{array}$ & $\begin{array}{l}227 \\
212 \\
275 \\
238\end{array}$ & $\begin{array}{l}214 \\
213 \\
263 \\
230\end{array}$ & $\begin{array}{l}228 \\
214 \\
264 \\
235\end{array}$ & $\begin{array}{l}312 \\
246 \\
364 \\
307\end{array}$ & $\begin{array}{l}290 \\
230 \\
318 \\
279\end{array}$ & $\begin{array}{l}318 \\
231 \\
315 \\
288\end{array}$ & $\begin{array}{l}.53 \\
.73 \\
.78 \\
.68\end{array}$ & $\begin{array}{l}.43 \\
.78 \\
.97 \\
.73\end{array}$ & $\begin{array}{l}.73 \\
.71 \\
.90 \\
.78\end{array}$ & $\begin{array}{l}1.38 \\
1.70 \\
1.92 \\
1.67\end{array}$ & $\begin{array}{l}1.16 \\
1.35 \\
2.13 \\
1.55\end{array}$ & $\begin{array}{l}1.70 \\
1.03 \\
1.92 \\
1.55\end{array}$ \\
\hline $.8-.8$ & $\begin{array}{l}\text { MC } \\
\text { RB } \\
\text { MT } \\
\text { Comp }\end{array}$ & $\begin{array}{l}225^{b} \\
202 \\
229^{c} \\
219\end{array}$ & $\begin{array}{l}237 \\
227 \\
228 \\
231\end{array}$ & $\begin{array}{l}234 \\
230 \\
236 \\
233\end{array}$ & $\begin{array}{l}268 \\
201 \\
278 \\
249\end{array}$ & $\begin{array}{l}260 \\
207 \\
243 \\
237\end{array}$ & $\begin{array}{l}242 \\
297 \\
266 \\
268\end{array}$ & $\begin{array}{r}1.55 \\
.74 \\
1.05 \\
.78\end{array}$ & $\begin{array}{l}.85 \\
.85 \\
.51 \\
.78\end{array}$ & $\begin{array}{l}.91 \\
.79 \\
.97 \\
.89\end{array}$ & $\begin{array}{l}.45 \\
.23^{\mathrm{a}} \\
.85 \\
.51\end{array}$ & $\begin{array}{l}.59 \\
.10^{\mathrm{c}} \\
.40 \\
.36\end{array}$ & $\begin{array}{l}.28^{\mathrm{a}} \\
.13^{\mathrm{b}} \\
.23^{\mathrm{b}} \\
.21\end{array}$ \\
\hline
\end{tabular}

Note: $a, b$, and $c$ denote the lesser $R T$ or $z$, comparing performance to $S_{1}$ and $S_{2}$ for that $S$, ISI and condition, at the .05, .01 and .00I levels respectively.

on that channel that produces the refractory effect (Davis, 1959).

\section{METHOD}

\section{Subjects}

One male (RB) and one female (MT) graduate student, and one male advanced undergraduate psychology student (MC), whose ages ranged from 19 to 25 , served as paid volunteers. Each served for 12 experimental sessions of approximately $1 \mathrm{~h}$ duration. $\mathrm{MC}$ and $\mathrm{RB}$ were co-investigators in the study. All three Ss had prior RT experience and course familiarity with RT findings and the PRP.

\section{Apparatus and Stimuli}

Stimulus events were presented on a three-channel Scientific Prototype Model GB tachistoscope. Each stimulus event (S-P) consisted of the appearance of a 46-min visual angle spot of light to the left and/or right of a central fixation point of like size. The stimulus events and fixation point were produced by back illumination of an opaque black card with an appropriately sized hole, placed in the front card holders of the tachistoscope. S-A consisted of the null event. Illumination was provided by a pair of Argon-Mercury bulbs located in each channel of the tachistoscope. The maximum width of the display was $3 \mathrm{deg} 20 \mathrm{~min}$ of visual angle. The luminance of the fixation point was $11 \mathrm{ft}-\mathrm{L}$ and the luminance of the stimulus events was $16 \mathrm{ft}-\mathrm{L}$, as measured by a SEI spot photometer. The warning signal was a .1-sec offset of the center spot that began a constant $2-\mathrm{sec}$ foreperiod delay. At the end of the foreperiod delay, the center spot again went off and remained off until the end of the trial, i.e., until $S$ had made both responses or $E$ had reset the apparatus.
Onset of the light in a given stimulus event channel simultaneously started a Hunter Klockounter through a system of Scientific Prototype dc-powered electronic buffers, reed relays, and flip-flops. S's response, a homolateral telegraph key depression, reset the appropriate flip-flop and stopped the Klockounter. A white-noise generator was used to mask relay clicks and other transients.

\section{Procedure}

Each trial was defined by the occurrence of $S_{1}-P$ or $S_{1}-A$ and $S_{2}-P$ or $S_{2}-A$. A session consisted of 300 trials at the same ISI (33, 67 , or $100 \mathrm{msec}$ ) and condition distinguished by $P\left(S_{1}\right)$ and $P\left(S_{2}\right)$ : (a) $\mathrm{P}\left(\mathrm{S}_{1}\right)=.8, \quad \mathrm{P}\left(\mathrm{S}_{2}\right)=.8 ; \quad$ (b) $\mathrm{P}\left(\mathrm{S}_{1}\right)=.8$, $\mathrm{p}\left(\mathrm{S}_{2}\right)=.4 ; \quad$ (c) $\mathrm{P}\left(\mathrm{S}_{1}\right)=.4, \quad \mathrm{P}\left(\mathrm{S}_{2}\right)=.8$; (d) $\mathrm{P}\left(\mathrm{S}_{1}\right)=.4, \mathrm{P}\left(\mathrm{S}_{2}\right)=.4$. In all cases, the occurrence of $S_{1}-P$ and $S_{2}-P$ were independent. Ss were instructed as to the ISI and condition for each session but knew only probabilistically if the trial would be $S_{1}-P$ and $S_{2}-P, S_{1}-P$ and $S_{2}-A$, etc. The order in which sessions were run was randomized separately for each $\mathrm{S}$ to minimize carry-over effects.

Warm-up trials were run to familiarize $S$ with the parameters employed for that session. Following the warm-up trials, 300 experimental trials were run with a rest period occurring in the middle of the session. Prior to each trial, $\mathrm{S}$ stated his $\mathrm{BH}$, e.g. " $S_{1}$ will occur but not $S_{2}$."

\section{RESULTS}

Three separate sets of analyses dealt with (a) effects of variation in $P(S)$,(b) effects of $\mathrm{BH}$, and (c) effects of presence or absence of a stimulus event upon performance to the alternative event.
Preliminary examination of the relation between $R T$ as a function of $P(I)$ revealed a marked positive acceleration. Transformation of $P(I)$ to normal deviate form largely eliminated the extent of this curvilinearity. Consequently, except for certain tests, inhibition data were analyzed and reported in terms of the transformed values, to be denoted $Z_{1}$ and $Z_{2}$.

\section{Analysis of Probability Effects}

The mean values of $R T$ and $Z$ are presented in Table 1 as a function of condition and ISI, separately for each $S$ and as a composite. To examine differences in performance to $S_{1}$ and $S_{2}$ (order effects), $t$ tests were conducted upon the $\mathrm{RT}_{1}$ and $\mathrm{RT}_{2}$ means in the .8-.8 and .4-.4 conditions, with respective of of 476 and 238. The observations were considered to be unrelated in view of the independent occurrence of $S_{1} \cdot P$ and $S_{2}-P$. Also run were $\mathrm{Z}$ tests comparing the corresponding values of $P(I)$ upon which the $z$ values were based. The tests were not conducted in the remaining two conditions because order effects are confounded with differences in $P(S)$. Significant differences are cited in Table 1 alongside the lesser $\mathrm{RT}$ or $\mathrm{Z}$.

As can be seen from this table, $R_{2}$ was never significantly faster than $R T_{1}$, and $Z_{2}$ was significantly greater than $Z_{1}$ in only one comparison. In contrast, there were four cases in which $\mathrm{RT}_{1}$ was significantly greater than $R_{2}$ and eight cases in which $Z_{1}$ was significantly greater than $Z_{2}$. Hence, the present analysis confirms the impression gathered from Table 1 that there is a delay in processing $S_{2}$ which, in part, defines the PRP.

Two sets of regression analyses were conducted upon the data in Table 1. The 


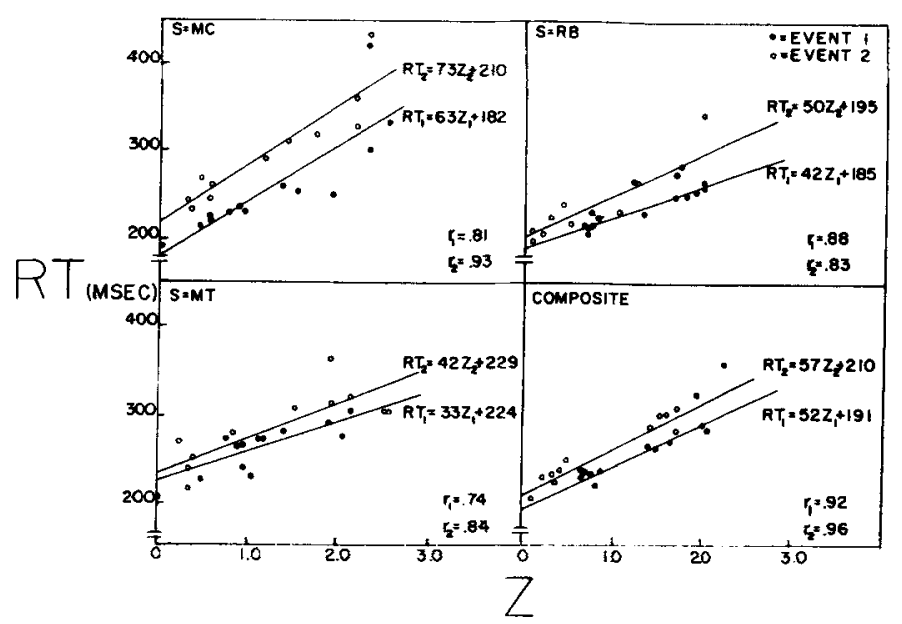

first of these, termed the common analysis, utilized all 24 data points per $S$ to determine a single value of 4 ( 3 ISIs $\times 4 \times 2$ events). Obtained in each of these analyses was the regression line in predicting $\mathrm{RT}$ from $\mathrm{z}$ and regressed RT scores, to be denoted $\mathrm{L}$ measures. Figure 1 presents the results of the separate analyses and scatter plots of data points in Table 1. As can be seen, the correlations were significant in all cases beyond the .01 level. The correlations derived from the common analyses were generally lower, but similar trends obtained.

The $\mathrm{L}$ measures derived from the common analysis were used to confirm the results of the separate $t$ and $z$ tests that the RT difference is not a function of differential error rate. Direct difference $t$ tests were run comparing corresponding ISI by Condition data points, separately for each $S$. The resultant values of $t$ were 7.93 $(p<.001), 2.75 \quad(p<.05)$ and 2.25 $(\mathrm{p}<.05)$ for MC, RB, and MT, respectively (all comparisons two-tailed, $\mathrm{d} f=11$ ). Thus, the deviations about the common regression line tended to be positive for $S_{2}$ and negatjve for $S_{1}$.

Because the order effects attenuated the correlations in the common analysis, $L$ measures were analyzed in the present and subsequent cases from the separate analyses. Four-way ANOVA $\left[\mathrm{P}\left(\mathrm{S}_{1}\right), \mathrm{P}\left(\mathrm{S}_{2}\right)\right.$, ISI, and Ss] were conducted upon the $\mathrm{RT}_{1}, \mathrm{RT}_{2}$,
$Z_{1}, Z_{2}, L_{1}$, and $L_{2}$ means. Summary values of $F$ derived from these analyses are presented in Table 2.

The significant effects of $P\left(S_{1}\right)$ upon $R_{1}$ and $Z_{1}$, and of $P\left(S_{2}\right)$ upon $Z_{1}, R T_{2}$, and $Z_{2}$ were in the expected direction as the performance measures were lower for $P(S)=.8$ than $P(S)=.4$. The $P\left(S_{1}\right)$ by $P\left(S_{2}\right)$ interaction arose because the effects of $\mathrm{P}\left(\mathrm{S}_{2}\right)$ were greater for $\mathrm{P}\left(\mathrm{S}_{1}\right)=.4$ than $P\left(S_{1}\right)=.8$. More important is the elimination of all probability effects with the regression analysis. Although $P(S)$ manipulation was not chosen under the assumption that its only effects were upon $S$ 's criterion, the lack of posterror-rate $P(S)$ effect suggests that such is the case. However, given the small number of $S s$ and $\mathrm{df}$, the usual limitations regarding acceptance-support statistical logic apply.

The lack of an ISI effect was surprising and disappointing. The data means for $\mathrm{RT}_{2}$ were 262,255 , and $254 \mathrm{msec}$ for $\mathrm{RT}_{1}$ and 289,262 , and 265 for $\mathrm{RT}_{2}$ at 33-, 67-, and $100-\mathrm{msec}$ ISIs, respectively. The mean $\mathrm{RT}_{2}$ decline of $24 \mathrm{msec}$ is slightly smaller than, but not out of range of, similar studies conducted in our laboratory. Also, ISI effects were obtained in other analyses to be reported below.

\section{Analysis of BH Data}

BH data were used to define fluctuating biases to respond to $S_{1}$ relative to $S_{2}$
Fig. 1. Scatter plots relating $R T$ to $z$, the normal deviate of $P(I)$, for $S_{1}$ (filled circle) and $S_{2}$ (open circle), separately for each $S$. Also presented for each $S$ are the separate regression lines for $R_{1}$ as a function of $Z_{1}$ and $R T_{2}$ as a function of $Z_{2}$ and the corresponding correlations between $R T$ and $z, r_{1}$ and $r_{2}$.

(Bernstein, Schurman, \& Forester, 1967). Pretrial reports were classified into three categories: (a) The hypothesis that $S_{1}-P$ and $S_{2}-A$ would occur, denoted BH-1, which implies a bias to responding to $S_{1} ;$ (b) the hypothesis that $S_{1}-A$ and $S_{2}-P$ would occur, denoted BH-2, which implies a bias in responding to $S_{2} ;(c)$ the hypothesis that $S_{1}-A$ and $S_{2}-A$ or $S_{1}-P$ and $S_{2}-P$ occur, denoted BH-0, which implies the absence of a differential bias to respond to $S_{1}$ or $S_{2}$. The resulting values of $R T$ and $z$ are presented in Table 3 as a function of ISI, separa tely for each $S$ and as a composite.

Inspection of Table 3 indicates that changes in RT and $\mathrm{z}$ are as expected from the assumption that the pretrial hypothesis does in fact denote a differential bias. $\mathrm{RT}_{1}$ and $\mathrm{Z}_{1}$ were lowest for $\mathrm{BH}-1$ and highest for $\mathrm{BH}-2$, whereas the reverse held for $\mathrm{RT}_{2}$ and $Z_{2}$. RT and $z$ values were then compared under equivalent BH levels as a function of order. That is, $\mathrm{RT}_{\mathbf{1}} \cdot \mathrm{BH}-1$ was compared with $\mathrm{RT}_{2}-\mathrm{BH}-2, \mathrm{RT}_{1}-\mathrm{BH}-2$ with $\mathrm{RT}_{2} \cdot \mathrm{BH}-1$, $\mathrm{RT}_{1}-\mathrm{BH}-0$ with $\mathrm{RT}_{2}-\mathrm{BH}-0$, etc., for $\mathrm{z}$, separately for each ISI and S. For MC, RT 1 was faster than $\mathrm{RT}_{2}$ in seven of nine comparisons $(p<.001$ in five cases, $p<.01$ in one case, and $p<.05$ in one case). Also, $\mathrm{Z}_{1}$ was higher in one comparison $(\mathrm{p}<.05)$. For RB, RT 1 was faster in two comparisons $(\mathrm{p}<.001$ and $\mathrm{p}<.05)$. However, in these two cases, $Z_{1}$ was also higher than $Z_{2}$ $(\mathrm{p}<.001)$, as well as in an additional three cases $(p<.001$ in two cases, $p<.05$ in one case). For MT, $\mathrm{RT}_{1}$ was faster in four cases ( $\mathrm{p}<.001$ in three cases, $\mathrm{p}<.05$ in one case) and $\mathrm{RT}_{2}$ was faster in two cases $(\mathrm{p}<.001$ and $p<.05)$. These latter two cases are the only two in any of the comparisons to be reported in which a significantly faster $\mathrm{RT}_{2}$ was not accompanied by a lower $\mathbf{Z}_{2}$.

As in the case of the probability analysis, ANOVAs were run for each of the six

Table 2

Summary Values of $F$ Derived from Analysis of Probability Effects

\begin{tabular}{|c|c|c|c|c|c|c|c|}
\hline \multirow[b]{2}{*}{ Source } & \multicolumn{7}{|c|}{ Measure } \\
\hline & df & $\mathrm{RT}_{1}$ & $\mathrm{z}_{1}$ & $\mathbf{L}_{1}$ & $\mathbf{R T}_{2}$ & $Z_{2}$ & $\mathbf{L}_{2}$ \\
\hline $\begin{array}{l}P\left(S_{1}\right)-A \\
P\left(S_{2}\right)-B \\
\text { ISI-C } \\
\text { AB } \\
A C \\
\text { BC } \\
\text { ABC }\end{array}$ & $\begin{array}{l}1 \\
1 \\
2 \\
1 \\
2 \\
2 \\
2\end{array}$ & $\begin{array}{l}25.64^{*} \\
3.95 \\
<1 \\
1.70 \\
<1 \\
<1 \\
<1\end{array}$ & $\begin{array}{l}123.90^{* * *} \\
\quad 4.56 \\
<1 \\
8.43^{* *} \\
<1 \\
<1 \\
<1\end{array}$ & $\begin{array}{l}<1 \\
1.8 \\
<1 \\
1.17 \\
<1 \\
<1 \\
<1\end{array}$ & $\begin{array}{l}<1 \\
38.45 \\
2.16 \\
7.12^{*} \\
1.48 \\
<1 \\
<1\end{array}$ & $\begin{array}{c}3.12 \\
185.94^{* *} \\
3.13 \\
4.14^{*} \\
<1 \\
<1 \\
<1\end{array}$ & $\begin{array}{l}<1 \\
<1 \\
1.56 \\
3.27 \\
1.09 \\
1.25 \\
<1\end{array}$ \\
\hline
\end{tabular}


Table 3

RT and $z$ as a Function of Criterion and ISI, Separately for Each $S$ and as a Composite

\begin{tabular}{|c|c|c|c|c|c|c|c|c|}
\hline \multirow[b]{2}{*}{ BH } & \multirow[b]{2}{*}{$\mathbf{S}$} & & \multicolumn{3}{|c|}{$\begin{array}{r}S_{1} \\
\text { ISI }\end{array}$} & \multicolumn{3}{|c|}{$\begin{array}{r}S_{2} \\
\text { ISI }\end{array}$} \\
\hline & & & 33 & 67 & 100 & 33 & 67 & 100 \\
\hline 1 & $\begin{array}{l}\text { MC } \\
\text { RB } \\
\text { MT } \\
\text { Comp }\end{array}$ & $\begin{array}{l}\text { RT } \\
\text { z } \\
\text { RT } \\
\text { z } \\
\text { RT } \\
\text { z } \\
\text { RT } \\
\text { z }\end{array}$ & $\begin{array}{r}234 \\
.87 \\
207 \\
.87 \\
245 \\
1.08 \\
229 \\
.94\end{array}$ & $\begin{array}{r}216 \\
.87 \\
207 \\
.91 \\
247 \\
1.34 \\
223 \\
1.04\end{array}$ & $\begin{array}{r}222 \\
1.12 \\
200 \\
.87 \\
246 \\
.99 \\
223 \\
.99\end{array}$ & $\begin{array}{r}349 \\
2.05 \\
266 \\
1.75 \\
338 \\
1.87 \\
318 \\
1.89\end{array}$ & $\begin{array}{r}333 \\
1.87 \\
254 \\
1.28 \\
315 \\
2.05 \\
301 \\
1.73\end{array}$ & $\begin{array}{r}338 \\
2.05 \\
266 \\
1.12 \\
324 \\
2.05 \\
309 \\
1.74\end{array}$ \\
\hline 2 & $\begin{array}{l}\text { MC } \\
\text { RB } \\
\text { MT } \\
\text { Comp }\end{array}$ & $\begin{array}{l}\text { RT } \\
\text { z } \\
\text { RT } \\
\text { z } \\
\text { RT } \\
\text { z } \\
\text { RT } \\
\text { z }\end{array}$ & $\begin{array}{r}324 \\
1.64 \\
264 \\
1.75 \\
288 \\
1.87 \\
292 \\
1.75\end{array}$ & $\begin{array}{r}291 \\
2.05 \\
281 \\
2.05 \\
298 \\
1.64 \\
290 \\
1.91\end{array}$ & $\begin{array}{r}285 \\
1.12 \\
259 \\
2.32 \\
294 \\
2.05 \\
279 \\
1.83\end{array}$ & $\begin{array}{r}270 \\
.87 \\
237 \\
.91 \\
253 \\
1.03 \\
253 \\
.74\end{array}$ & $\begin{array}{r}236 \\
.67 \\
222 \\
.64 \\
229 \\
.95 \\
229 \\
.75\end{array}$ & $\begin{array}{r}213 \\
.61 \\
203 \\
.58 \\
220 \\
.67 \\
212 \\
.62\end{array}$ \\
\hline 0 & $\begin{array}{l}\text { MC } \\
\text { RB } \\
\text { MT } \\
\text { Comp }\end{array}$ & $\begin{array}{l}\text { RT } \\
\text { z } \\
\text { RT } \\
\text { z } \\
\text { RT } \\
\text { z } \\
\text { RT } \\
\text { z }\end{array}$ & $\begin{array}{r}256 \\
1.17 \\
226 \\
1.40 \\
253 \\
1.12 \\
245 \\
1.21\end{array}$ & $\begin{array}{r}247 \\
1.28 \\
236 \\
1.34 \\
247 \\
1.03 \\
243 \\
1.22\end{array}$ & $\begin{array}{r}248 \\
1.22 \\
240 \\
1.34 \\
257 \\
1.12 \\
248 \\
1.23\end{array}$ & $\begin{array}{r}284 \\
1.03 \\
241 \\
.99 \\
280 \\
1.34 \\
268 \\
1.12\end{array}$ & $\begin{array}{r}270 \\
.99 \\
223 \\
.77 \\
253 \\
1.08 \\
249 \\
.95\end{array}$ & $\begin{array}{r}243 \\
.95 \\
213 \\
.80 \\
257 \\
.87 \\
238 \\
.87\end{array}$ \\
\hline
\end{tabular}

dependent variables. $L$ measures were defined as in the probability analysis, using separate regression lines for the nine cells ( 3 ISIs by 3 criteria). The correlations between $R T$ and $z$ for $S_{1}$ and $S_{2}$ were .74 $(\mathrm{p}<.05)$ and $.96(\mathrm{p}<.01)$ for $\mathrm{MC}, .92$ $(\mathrm{p}<.01)$ and $.87(\mathrm{p}<.01)$ for $\mathrm{RB}$, and .91 $(p<.01)$ and $.95(p<.01)$ for MT (all $p<.05)$. The results of these ANOVA were that the three criteria varied beyond the .01 level significantly for $\mathrm{RT}_{1}(\mathrm{~F}=69.76), \mathrm{Z}_{1}$ $(F=24.32), \quad R_{2} \quad(F=64.04)$, and $Z_{2}$ $(F=69.66), \mathrm{df}=2,16 . \mathrm{RT}_{2}$ declined across ISIs $[F(2,16)=7.68, p<.01]$ as did $Z_{2}$ $[F(2,16)=3.63, p<.05]$. However, when the error-rate correction was made, none of the effects were significant. Thus, although no specific assumption was made regarding the mechanism by which BH influences RT, the hypothesis of a criterion effect is also suggested.
Several additional analyses of the $\mathrm{BH}$ data were conducted. These included $\mathrm{RT}$ and $\mathrm{z}$ as a function of correct and incorrect $\mathrm{BH}$, a further analysis of the criterion data contrasting performance to the two types of BH-O and separately for the various probability levels. These results neither contributed much of additional relevance to the PRP nor conflicted with the above results.

Analysis as a Function of Presence vs Absence of an Alternative Stimulus Event

Because of the implication of Davis's (1959) "attention" hypothesis above, RT and $z$ were obtained separately for trials on which the alternative event occurred vs when it did not occur. The data means are presented in Table 4. Comparisons of comparable order effects were similar to those already described in that 4,1 , and 1 comparisons were faster for $\mathbf{R T}_{1}$; and 0,2 , and 0 were the reverse, 2,3 , and 1 values of $Z_{1}$ were greater than $Z_{2}$, and none the reverse, for MC, RB, and MT, respectively, with a minimum $p$ of .05 .

ANOVAs (S-P vs S-A, ISI and Ss) were conducted for the six dependent variables as above. None of the effects were significant for $\mathrm{RT}_{1}$ or $\mathrm{Z}_{1}$ although the trends were towards higher values of $R T_{1}$ and $Z_{1}$ for $S_{2}-A$ as opposed to $S_{2} \cdot P \cdot R_{2}$ declined with ISI as in the criterion analysis $[F(2,10)=5.61, p<.05] . \quad Z_{2}$ was also higher for $S_{1}-A$ as opposed to $S_{1}-P$ $[F(1,10)=31.02, p<.01]$ and also showed a slight, but nonsignificant, decline with ISI. The correlations between $\mathrm{RT}$ and $\mathrm{z}$ were -.31 and .34 for MC, .73 and .34 for RT, and .77 and .05 for MT $(p<.05$ in all cases, $\mathrm{df}=4$ ). Consequently, the $\mathrm{L}$ measures have not been presented. The major finding of this analysis is, therefore, that making a response to $S_{1}$ did not seem to interfere with performance to $S_{2}$.

\section{DISCUSSION}

The results clearly describe a sensitivity decrement in $S_{2}$ processing ability. Although the ISI effect is somewhat equivocal, evidence of a decline in $\mathrm{RT}_{2}$ was noted in two of three analyses. However, the attenuation of the effects of various stimulus manipulations with error-rate correction does imply that criterion effects play a substantial role in complex RT tasks. Also of note is the lack of decrement in processing $S_{2}$ for $S_{1} \cdot P$ as opposed to $S_{1}-A$.

Bernstein, Blake, and Hughes (1968) found no difference between $\mathrm{RT}_{1}$ and $\mathrm{RT}_{2}$ at 100 -msec ISI in an event-certain, fixed ISI task. The discrepancy with the present finding may have emerged from differences in the refractory limits imposed by differential task demands. On the other hand, it was not possible to isolate criterion effects in the earlier study as the absence of choice virtually precluded the possibility of error. As the present results were that $P\left(I_{2}\right)$ tended to decline with ISI, an alternate

Table 4

RT and $z$ as a Function of Presence vs Absence of Alternative Stimulus Event

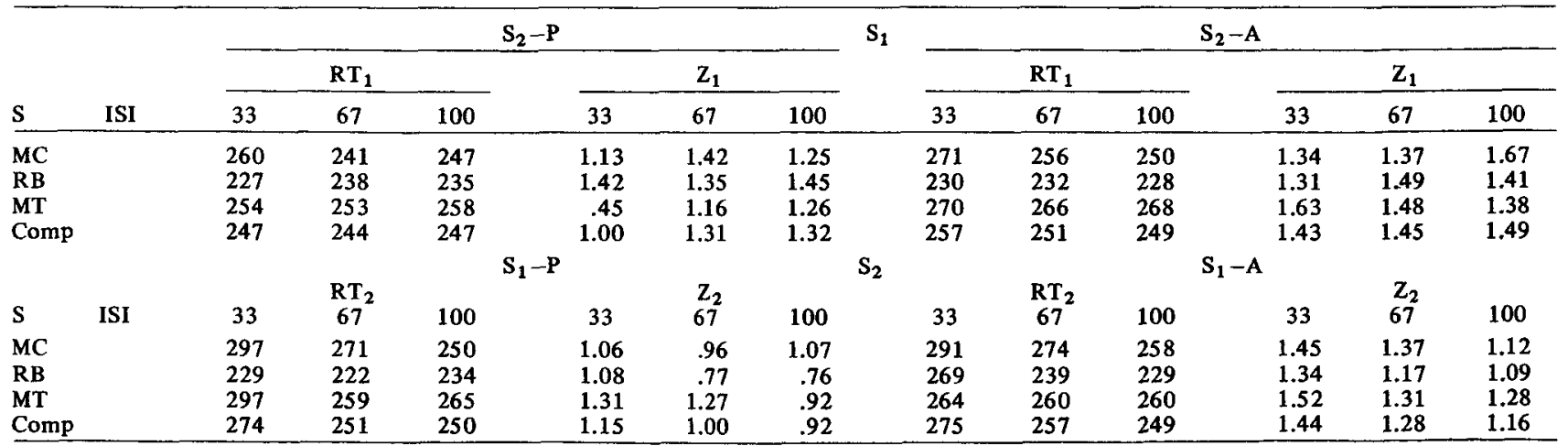


interpretation of the discrepancy is that Ss tended to adopt a more lenient criterion in responding to $\mathrm{S}_{2}$ with ISI.

More recently, Bernstein and Clark (1968) used a sequential Type C task to evaluate modality effects in the PRP. Depending upon condition, $S_{1}-P$ was always a visual event. Similar delays were found in processing $\mathrm{S}_{2}$ for visual-visual sequences, supporting the sensitivity-decrement position and $R T_{2}$ and $Z_{2}$ was lower with $S_{1}-P$ than $S_{1}-A$. Perhaps the reason that the presence of a first event did not interfere with performance in our studies as it did in other studies (Davis, 1959) is that the presence-absence variable was manipulated randomly within a sequence of trials, whereas in earlier studies it was manipulated across separate blocks of trials. The results of the Bernstein and Clark (1968) experiment are of relevance for an additional reason. The Ss were not generally familiar with the PRP literature and pretrial verbal reports were not obtained. Hence, neither factor is responsible for the principal effects in the present study.

An incidental finding of potential interest is the steeper slope for the $\mathrm{RT}-\mathrm{z}$ regression line for $S_{2}$ as opposed to $S_{1}$ (Fig. 1). The slope difference by definition implies a greater increment in $\mathrm{RT}_{2}$ per unit increment in $P\left(I_{2}\right)$. In other words, Ss profited less by adopting a stricter criterion for $S_{2}$ than they did for $S_{1}$. This finding suggests a differential efficiency in separating $S-P$ from S-A. Such a source of decrement is clearly different from that implied by single-channel theory, which would have $S_{1}$ and $S_{2}$ processed at the same rate except for the en route delay peculiar to the latter.
Pending further examination, the slope difference merely raises the possibility of an additional interpretation of the PRP. The remaining aspects of the data are essentially in accord with contemporary versions of single-channel theory that assume only one stage in processing to be responsible for the PRP (Smith, 1967; Bernstein, Blake, \& Hughes, 1968). Whether or not a preparatory-state theory predicts a diminution in sensitivity is not entirely clear from the current statements of the theory. Clearly, readiness to respond cannot be interpreted simply as a drop in inertia favoring overt execution of a response over inhibition.

Another version of preparatory-state theory based upon the role of temporal expectancies cannot be ruled out. Such a theory would have to be modified to consider subjective rather than objective time uncertainty. One experimental advantage to the use of fixed ISIs, providing appropriate safeguards are present to rale out anticipatory responding, etc., is that the effects induced by randomization of ISIs (Nickerson, 1965) are eliminated. On the other hand, physical time certainty cannot be equated with a $S$ 's perfect timekeeping ability event over a set of constant, short ISIs. What would seem to be most needed regarding preparatory state theories is a more careful application of the terms "readiness" and "subjective time uncertainty."

\section{REFERENCES}

BERNSTEIN, I. H., BLAKE, R. R., \& HUGHES, $M, H$. Effects of time and event uncertainty upon sequential information processing. Perception \& Psychophysics, 1968, 3, 177-184.
BERNSTEIN, I. H., \& CLARK, M.H. Time sharing and intermodal information processing. Paper presented at Psychonomic Society Convention, 1968.

BERNSTEIN, I. H., SCHURMAN, D. L., \& FORESTER, G. Choice reaction time as a function of stimulus uncertainty, response uncertainty, and behavioral hypotheses. Joumal of Experimental Psychology, 1967, 74, 517-524.

DAVIS, $R$. The role of "attention" in the psychological refractory period. Quarterly Journal of Experimental Psychology, 1959, 11, 211-220.

FITTS, P. M. Cognitive aspects of information processing: III. Set for speed over accuracy. Journal of Experimental Psychology, 1966, 71, 849-857.

GRICE, G. R. Stimulus intensity and response evocation. Psychological Review, 1968, 75, 359-373.

LUCE, R. D. Detection and recognition. In R. D. Luce, R. R. Bush, and E. Galanter (Eds.), Handbook of mathematical psychology. Vol. 1 . New York: Wiley, 1963. Pp. 103-190.

MCGILL, W. Stochastic latency mechanisms. In R. D. Luce, R. R. Bush, and E. Galanter (Eds.), Handbook of mathematical psychology. Vol. 1. New York: Wiley, 1963. Pp. 309-361.

SMITH, M. C. Theories of the psychological refractory period. Psychological Bulletin, 1967, 67, 202-213.

YELLOTT, J. I. Correction for guessing in choice reaction time. Psychonomic Science, 1967, 8, 321-322.

\section{NOTES}

1. Supported by NIMH Grant MH-12530.

2. Address: Department of Psychology, The University of Texas at Arlington, Arlington, Texas 76010.

3. Now at Vanderbilt University.

(Accepted for publication April 29, 1969.) 